\title{
Chaotic Dynamics of Modified Wien Bridge Oscillator with Fractional Order Memristor
}

\author{
Karthikeyan RAJAGOPAL ${ }^{1,2}$, Chunbiao $L^{3}{ }^{3}$, Fahimeh NAZARIMEHR ${ }^{4}$, \\ Anitha KARTHIKEYAN ${ }^{1}$, Prakash DURAISAMY ${ }^{1}$, Sajad JAFARI ${ }^{5}$ \\ ${ }^{1}$ Center for Nonlinear Dynamics, Defence University, Ethiopia \\ ${ }^{2}$ Institute of Energy, Mekelle University, Ethiopia \\ ${ }^{3}$ Jiangsu Key Laboratory of Meteorological Observation and Information Processing, Nanjing University of Information \\ Science \& Technology, Nanjing 210044, China \\ ${ }^{4}$ Dept. of Biomedical Engineering, Amirkabir Uiversity of Technology, Iran \\ ${ }^{5}$ Nonlinear Systems and Appliations, Faculty of Electrical and Electronics Engineering, Ton Duc Thang University, \\ Ho Chi Minh City, Vietnam \\ sajad.jafari@tdtu.edu.vn
}

Submitted February 8, 2019 / Accepted February 19, 2019

\begin{abstract}
In this paper a modified third order Wien bridge oscillator with fractional order memristor is proposed. Various dynamical properties of the proposed oscillator are investigated such as equilibrium points, Eigenvalues, Lyapunov exponents and bifurcation diagrams. The Lyapunov spectrum of the system for various values of fractional order is derived. Using forward and backward continuation methods of plotting bifurcation diagram, the multistability of the oscillator is investigated. The proposed oscillator is realized using Field Programmable Gate Arrays and the experiment is conducted using hardwaresoftware co-simulation.
\end{abstract}

\section{Keywords}

Wien bridge oscillator, memristor, bifurcation, multistability, fractional order

\section{Introduction}

Chaos is one of the most interesting topics in nonlinear dynamics in recent decades [1-4]. Many researches have been done about understanding the mechanism of generation of chaotic attractors [5-8]. Chaotic attractors were considered in relation with saddle point equilibria [9], [10] till some counter examples discovered [11-14]. After that many studies have been done to investigate the effect of equilibrium points on the generation of chaotic dynamics [2], [14], [15]. Currently many researchers are working on the chaotic dynamics since there are many unsolved issues in this area [16-18]. Chaotic electronic circuits are very interesting in this area [19].

The ability to store the state or information of any system at a given time, and access it at a later time is defined as memory. Some dynamical properties of the constituents of condensed matter, namely electrons and ions are influenced by a memory state. The memristor has the memory which means it remembers its last resistance (state). If the power turns back on again, the resistance of the memristor starts exactly from where it was turned off. Chua in 1971 realized the existence of memristor [20]. The V-I characteristics of memristor look like Lissajous pattern (pinched hysteresis loop). Thus, Chua concluded that memristor has nonlinear behavior. The 'pinched hysteresis loop' of the memristor shrinks while the excitation frequency increases [21], [22]. Memristors are categorized to three models as ideal flux or charge controlled memristors, generalized voltage controlled memristors, and non-ideal voltage controlled memristors. Various nonlinear circuits were formulated and dynamical behaviors were investigated based on these models [23-26].

The past history of the memristor current such as the time integral of the current is effective on the memristance. Due to the fractional interaction between flux and charge, many memristors cannot be treated as ideal ones [27], [28]. It is nearly impossible to understand the physical behavior of the circuit with memristors without the use of a properly modelled non-ideal memristor. By controlling fractional parameters exist in a fractional order memristor system, the saturation time of the resistance can be controlled [29]. In [30] the chaotic behavior of a system with fourth degree polynomial memresistance function has been investigated. By treating both integer order and fractional order it was concluded that fractional-order treatment can expose intricate chaotic behavior with lower order than the integerorder treatment. In [28] a two segment memristor has been investigated as a spin-transfer torque (STT) junction. The study has revealed that the integer order model showed symmetrical rectangular resistance hysteresis loop while the fractional order model exhibited non-symmetrical resistance hysteresis loop which resembled closer to the real time hysteresis loop. In [31] memristor based Wien oscillator has been formulated and nonlinear characteristics have been studied. Voltage-controlled memristor emulator-based 
Chua's circuit and its dynamical properties have been investigated particularly effect of coexisting multiple attractors [24], [32], [33]. Coexistence of multiple attractors is called multistability. This property is undesirable and dangerous in some engineering application. Contradictorily in some cases it is advantageous. It is very important to investigate the chaotic systems for such a phenomenon [34-36]. By transforming the parallel resistor and capacitor (RC) feedback network to a series RC feedback network a simple third-order Wien-bridge oscillator has been developed in [37]. The investigation confirms the existence of bistability phenomenon in this system.

Many researches have been carried out in the last decade on fractional order systems and their applications [38-40]. Numerical methods to simulate fractional-order nonlinear system have been proposed in [41], and Matlab solutions for fractional-order chaotic systems have been discussed in [42]. Field Programmable Gate Array (FPGA) implementation of chaotic systems has been a hot topic recently [43-45].

Motivated by the above discussions, we are proposing a modified third order Wien bridge oscillator with fractional order memristor. Various dynamical analyses are presented to prove the existence of chaotic oscillations. An FPGA implementation of the proposed system is done to prove its hardware realisability.

\section{Fracmemristor Wien Bridge Oscillator (FWO)}

Chua in 1971 introduced a memristor [20]. Later the mathematical model of the memristor was proposed in [46]. The mathematical model of a memristor is as follows,

$$
\begin{aligned}
& y(t)=F_{\mathrm{M}}(\phi, u, t) u(t), \\
& \dot{\phi}(t)=G(\phi, u, t)
\end{aligned}
$$

where $\phi$ is the internal state of the memristor. The application of a voltage-controlled model of memristor to construct a third order Wien bridge oscillator is studied in [47]. The internal state was taken as $\dot{\phi}(t)=-V_{\mathrm{m}}-\phi\left[h-V_{\mathrm{m}}^{2}\right]$, where $V_{\mathrm{m}}$ is the voltage across the memristor. It was considered to be a passive memristor. The memductance function was considered as $W(\phi)=\alpha\left(\phi^{2}+\beta\right)$. The modified memristor is as follows,

$$
\begin{aligned}
& i_{\mathrm{m}}=\left(1+c \phi^{2}\right) V_{\mathrm{m}}, \\
& \dot{\phi}=-V_{\mathrm{m}}-\phi\left[h-V_{\mathrm{m}}^{2}\right]
\end{aligned}
$$

where $i_{\mathrm{m}}$ is the current of memristor. In order to reduce complexity, we assume $\alpha=c, \alpha \beta=1$. follows,

$$
\begin{aligned}
& i_{\mathrm{m}}=\frac{1}{R_{1}}\left(1+\frac{R_{0}}{R_{8}} \phi^{2}\right) V_{\mathrm{m}}, \\
& \dot{\phi}=\frac{1}{R_{4} c_{1}}\left(-V_{\mathrm{m}}-\frac{R_{4}}{R_{2}} \phi+\frac{R_{4}}{R_{3}} V_{\mathrm{m}}^{2} \phi\right) .
\end{aligned}
$$

Many studies have been done on the complex features of fractional order chaotic systems like multistability, megastability and bispectrum [48], [49]. Here we investigate a fractional order memristor (called Fracmemristor) which is derived by replacing the integer order differentiator to a fractional order differentiator. The fractional order memristor [44] is defined as,

$$
\begin{aligned}
& i_{\mathrm{m}}=\frac{1}{R_{1}}\left(1+\frac{R_{0}}{R_{8}} \phi^{2}\right) V_{\mathrm{m}}, \\
& D^{q} \phi=\frac{1}{R_{4} c_{1}}\left(-V_{\mathrm{m}}-\frac{R_{4}}{R_{2}} \phi+\frac{R_{4}}{R_{3}} V_{\mathrm{m}}^{2} \phi\right) .
\end{aligned}
$$

Using the above definition of a fractional order memristor [44], a third order Wien bridge oscillator is derived based on the one proposed in [47] as shown in Fig. 1. The circuit's equations are as follows,

$$
\begin{aligned}
& C_{1} \dot{V}_{1}=\frac{\frac{R_{1}}{R_{2}} V_{1}-V_{2}}{R_{3}}-\left(1+c \phi^{2}\right) V_{1}, \\
& C_{2} \dot{V}_{2}=\frac{\frac{R_{1}}{R_{2}} V_{1}-V_{2}}{R_{3}}, \\
& D^{q} \phi=-V_{1}-h\left(\phi-V_{1}^{2}\right)
\end{aligned}
$$

where $q$ is the fractional order and $V_{1}, V_{2}$ are the voltages across the Fracmemristor [30] and capacitor $C_{1}$, respectively.

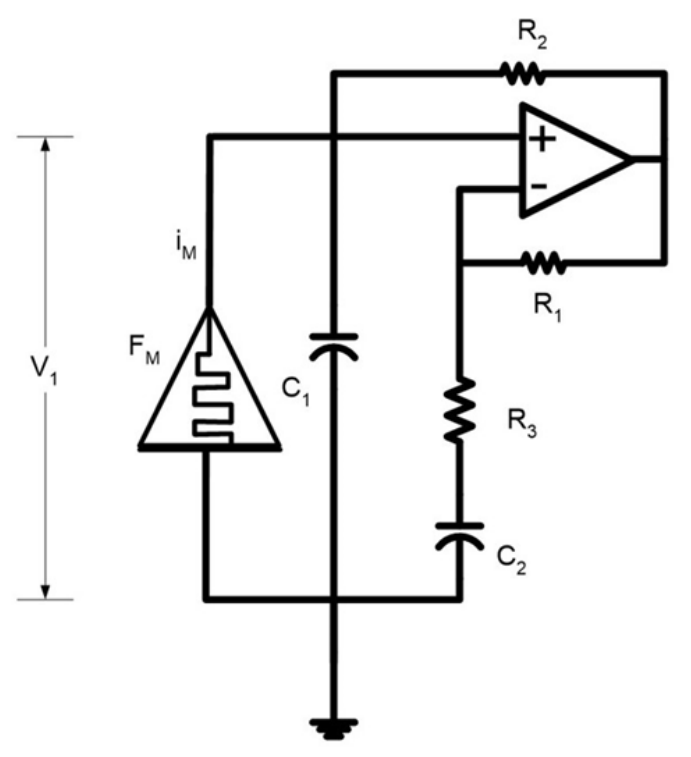

Fig. 1. Wien bridge oscillator with fractional order memristor. 
By assuming $x=V_{1}, \quad y=V_{2}, \quad z=\phi, \quad C_{1}=C_{2}=C$, $a=R_{1} /\left(R_{2} R_{3} C\right), \quad b=1 /\left(R_{3} C\right), \quad d=h$ the dimensionless model is as follows,

$$
\begin{aligned}
& \dot{x}=x\left[a-1-c z^{2}\right]-b y, \\
& \dot{y}=a x-b y, \\
& D^{q} z=-x-z\left[d-x^{2}\right] .
\end{aligned}
$$

The FWO model (6) is discretized using the predictorcorrector method [50], [51]. The Adams-Bashforth-Moulton (ABM) algorithm [52] is considered to be effective when highly sensitive systems are considered. In this section the predict-evaluate-correct-evaluate (PECE) method of ABM studied in [53] is used. The convergence and accuracy of this method were studied in [54]. In order to derive the general model of the PECE [50], [51] method, the fractional order dynamical system with order $q$ is considered as,

$$
D^{q} x=f(t, x), 0 \leq t \leq T
$$

where $x^{k}(0)=x_{0}^{k}$ for $k \in[0, n-1]$.

Equation (7) is similar to the Volterra integral equation [54] as,

$$
x(t)=\sum_{k=0}^{n-1} x_{0}^{k} \frac{t^{k}}{k !}+\frac{1}{\Gamma(q)} \int_{0}^{t} \frac{f(\tau, x)}{(t-\tau)^{1-q}} \mathrm{~d} \tau
$$

where $h=T / N$ and $t_{n}=n h$ as $h$ belongs to $[0, N]$. The discrete form of (8) can be defined as,

$$
\begin{aligned}
x_{h}\left(t_{n+1}\right) & =\sum_{k=0}^{n-1} x_{0}^{(k)} \frac{t_{n}^{k+1}}{k !}+\frac{h^{q}}{\Gamma(q+2)} f\left(t_{n+1}, x_{h}^{p}\left(t_{n+1}\right)\right) \\
& +\frac{h^{q}}{\Gamma(q+2)} \sum a_{j, n+1} f\left(t_{j}, x_{h}\left(t_{j}\right)\right)
\end{aligned}
$$

where

$$
\begin{gathered}
a_{j, n+1}=\left\{\begin{array}{cc}
n^{q+1}-(n-q)(n+1)^{q+1}, & j=0 \\
-2(n-j+1)^{q+1}, & 1 \leq j \leq n \\
1, & j=n+1
\end{array}\right. \\
x_{h}^{p}\left(t_{n+1}\right)=\sum_{k=0}^{n-1} x_{0}^{(k)} \frac{t_{n}^{k+1}}{k !}+\frac{h^{q}}{\Gamma(2)} \sum_{j=0}^{n} b_{j, n+1} f\left(t_{j} x_{h}\left(t_{j}\right)\right), \\
b_{j, n+1}=\frac{h^{q}}{q}\left((n-j+1)^{q}-(n-j)^{q}\right) .
\end{gathered}
$$

The error estimate is $e=\operatorname{Max}\left|x\left(t_{i}\right)-x_{h}\left(t_{i}\right)\right|=0\left(h^{p}\right),(j=0$ to $N)$, where $p=\operatorname{Min}(2,1+q)$. So, the discrete form of the third state of the FWO can be defined as,

$$
z_{n+1}=\left\{\begin{array}{l}
z_{0}+\frac{h^{q}}{\Gamma\left(q_{z}+2\right)}\left[-x_{n+1}^{p}-z_{n+1}^{p}\left(d-\left(x_{n+1}^{p}\right)^{2}\right)\right] \\
+\frac{h^{q}}{\Gamma(q+2)} \sum_{j=0}^{n}\left[\eta_{3, j, n+1}\left[-x_{j}-z_{j}\left(d-x_{j}^{2}\right)\right]\right]
\end{array}\right\}
$$
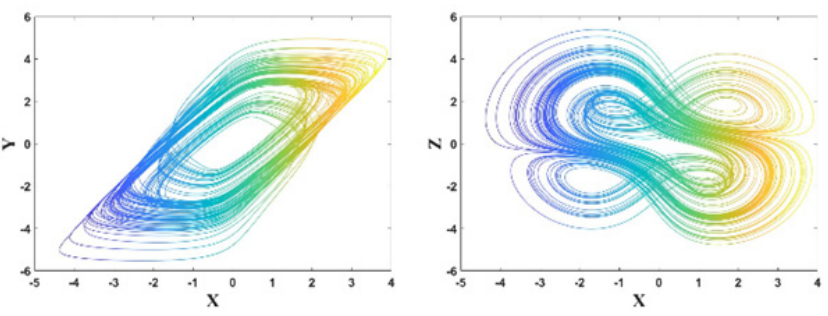

Fig. 2. $2 D$ projections of attractor of the FWO system in initial conditions $[0,1,0]$

where

$z_{n+1}^{p}=z_{0}+\frac{1}{\Gamma(q+2)} \sum_{j=0}^{n} \omega_{3, j, n+1}\left[-x_{j}-z_{j}\left(d-x_{j}^{2}\right)\right]$

and

$\eta_{l, j, n+1}=$
$\left\{\begin{array}{cc}n^{q_{i}+1}-\left(n-q_{i}\right)(n+1)^{q_{i}+1}, & j=0 \\ (n-j+2)^{q_{i}+1}+(n-j)^{q_{i}+1}-2(n-j+1)^{q_{i}+1}, & 1 \leq j \leq n \\ 1, & j=n+1\end{array}\right.$

$\omega_{l, j, n+1}=\frac{h^{q_{i}}}{q_{i}}\left[\left((n-j+1)^{q_{i}}-(n-j)^{q_{i}}\right), 0 \leq j \leq n\right]$

where $l=1$ and $\mathrm{i}=z$.

The fourth order Runge-Kutta method is used to solve the first two states of the FOW system (6). The third fractional order state is solved using PECE derived in (11). The 2D projections of attractor of the discretized FWO system (6) in $a=3, b=1, c=0.5, d=2$ and fractional order $q=0.95$ are shown in Fig. 2 .

\section{Dynamical Analysis of the FWO}

In this section, dynamical properties of the FWO such as the stability of equilibrium, Eigenvalues and Lyapunov exponents are discussed.

\subsection{Stability of Equilibrium Points}

To study the FOW system, the parameter $a$ is considered as the variable parameter and the other parameters are $b=1, c=0.5, d=2$. The FOW system has three equilibrium points as follows,

$$
\begin{aligned}
& E_{1}=[0,0,0], \\
& E_{2}=\left[x_{\mathrm{E}_{2}}, \frac{b}{a} x_{\mathrm{E}_{2}} ; \frac{x_{\mathrm{E}_{2}}}{\left(x_{\mathrm{E}_{2}}^{2}-d\right)}\right], \\
& E_{3}=\left[x_{\mathrm{E}_{3}}, \frac{b}{a} x_{\mathrm{E}_{3}} ; \frac{x_{\mathrm{E}_{3}}}{\left(x_{\mathrm{E}_{3}}^{2}-d\right)}\right]
\end{aligned}
$$

where

$x_{\mathrm{E}_{2}}=-\frac{\sqrt{\left(a-2\left(8 a^{4}-16 a^{3}-7.75 a^{2}+16 a+8\right)\right)}}{4\left(-a^{2}+a+1\right)}$, 


$$
x_{\mathrm{E}_{3}}=-\frac{\sqrt{\left(a+2\left(8 a^{4}-16 a^{3}-7.75 a^{2}+16 a+8\right)\right)}}{4\left(-a^{2}+a+1\right)} .
$$

Figure 3 shows the real part of Eigenvalues of the equilibrium points (13) with respect to changing parameter $a$. The figure shows that the equilibrium points $E_{2}$ and $E_{3}$ have negative real parts in $a \geq 3$ while they have zero real part for $a<3$. So both of these equilibriums are stable. The fixed point at origin $\left(E_{1}\right)$ has a positive real part and so it is an unstable saddle.

Corollary 1 If the dynamic of FWO is chaotic, the fixed point has to be unstable and hence, the necessary condition is

$$
q>\frac{2}{\pi} \arctan \left(\frac{|\operatorname{Im}(\lambda)|}{\operatorname{Re}(\lambda)}\right)
$$

for any $\lambda$ of the equilibrium points.

The Eigenvalues of the FWO at the equilibrium point $E_{1}$
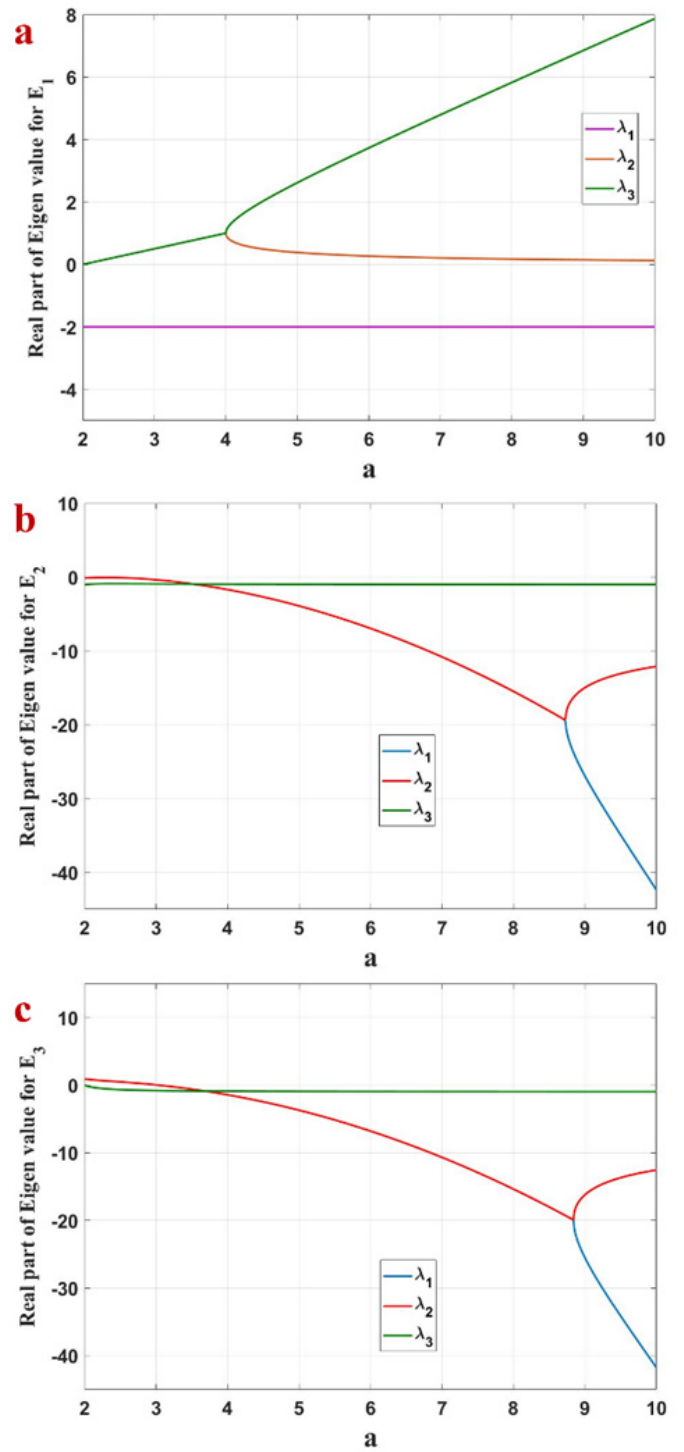

Fig. 3. Real part of Eigenvalues with respect to changing parameter $a$.

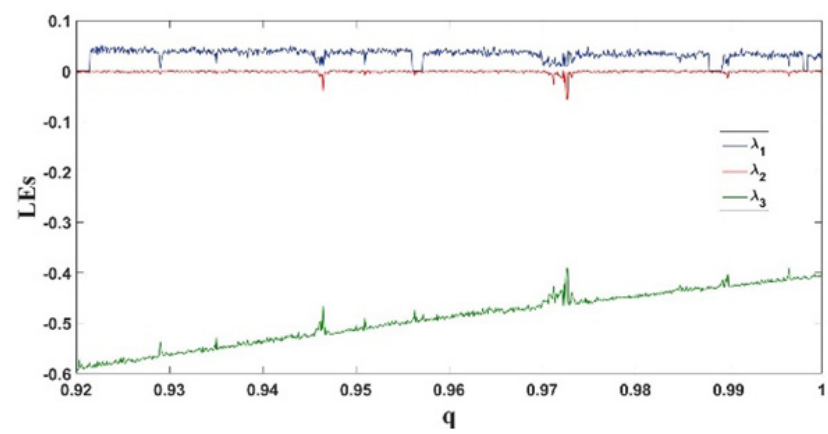

Fig. 4. Lyapunov spectrum of the FWO system with respect to changing $q$.

in $a=3$ are $\lambda_{1,2}=0.5000 \pm 0.8660 \mathrm{i}$ and $\lambda_{3}=-2$. In order to satisfy (14), we have $q_{i}>0.92$.

Corollary 2 To exist chaotic attractor in the FWO, the equilibrium points corresponding to the oscillations should exhibit instability. So the necessary condition for the existence of unstable equilibrium is

$$
\frac{\pi}{2 M}-\min _{i}\left\{\arg \left(\lambda_{i}\right)\right\} \geq 0
$$

where $\lambda_{i}$ are the roots of $\operatorname{det}\left(\operatorname{diag}\left(\lambda^{M q_{x}}, \lambda^{M q_{x}}, \lambda^{M q_{x}}\right) J_{E_{i}}\right)$ for each $E_{i}$.

Using Corollary 1 and Corollary 2, the FWO has chaotic dynamics in $q>0.92$ for $E_{1}$.

\subsection{Lyapunov Exponent}

Lyapunov exponent is an interesting tool to find chaotic dynamics [55]. Lyapunov exponents (LEs) of the FWO are derived using the Wolf's algorithm [56] and the fractional order predictor-corrector [53] solver fde12 [57] as the ode solvers [58]. Figure 4 shows Lyapunov exponents of the FWO with respect to changing fractional order $q$.

\subsection{Bifurcation}

Dynamical properties of the FWO with changing parameter $a$ and fractional order $q$ are discussed in this section. Firstly, bifurcation diagram with respect to changing parameter $a$ is derived. The fractional order of the FWO system is set to $q=0.95$. It is shown in Fig. 5 wherein maximum value of ' $Z$ ' variable is shown with respect to changing parameter $a$.

Secondly, bifurcation diagram of the FWO system with respect to changing fractional order $q$ is investigated. Figure 6 shows this bifurcation plot. We have plotted the maximum value of ' $\mathrm{X}$ ' variable with change in order $q$. Figure 4 shows the existence of chaos with positive Lyapunov exponents in some intervals of parameter $q$.

\subsection{Multistability}

Multiple coexisting attractors have been a research interest recently. The existence of multistability is checked 


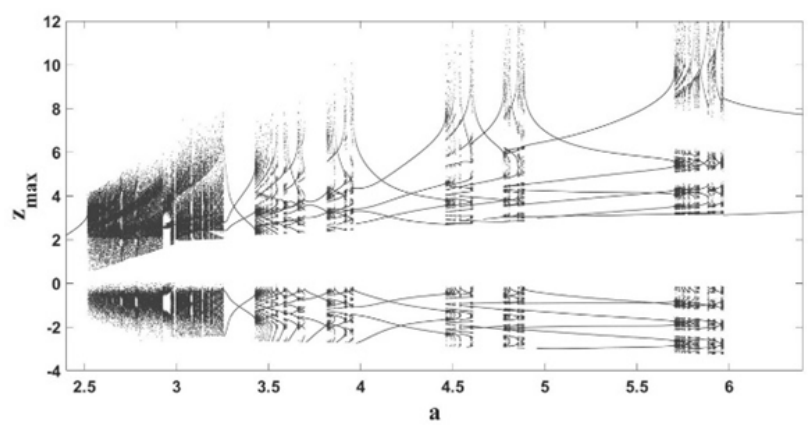

Fig. 5. Bifurcation of the FWO system with respect to changing parameter $a$.

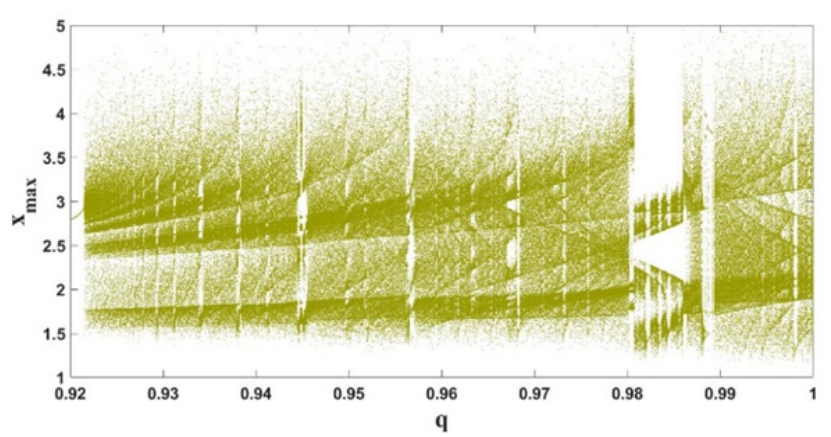

Fig. 6. Bifurcation of the FWO system with order $q$.

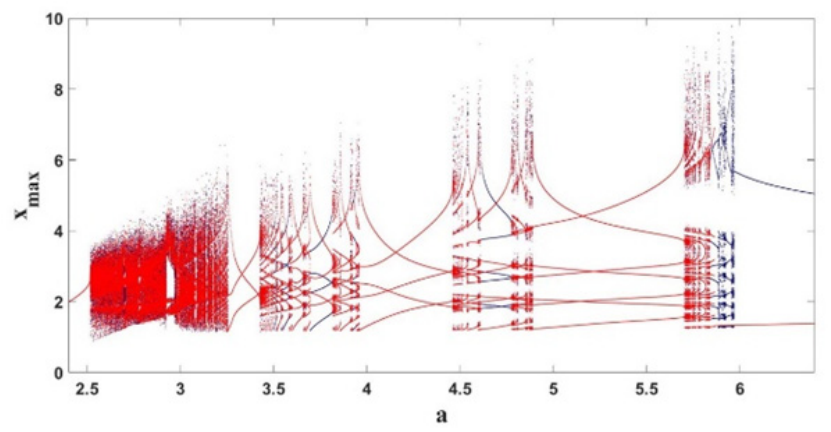

Fig. 7. Bifurcation diagram of the FWO system with respect to changing parameter $a$ using forward continuation (blue) and backward continuation (red).

by comparing the forward bifurcation where the parameter is increased with the reinitialization from the end value of state trajectory and backward bifurcation where the parameter is decreased. Figure 7 shows bifurcation diagram of the FWO system with forward continuation shown in blue dots and backward continuation shown in red dots. The figure shows that the system is multistable since the two bifurcations are not completely matched.

\section{FPGA Implementation of the FWO System}

There are many literatures on the integer order FPGA implementations. However, few studies have been done on fractional order FPGA implementations. FPGA implementation of fractional order chaotic systems with hidden oscillations have been implemented and the power efficiency analysis with various fractional orders are investigated in
[59]. The first two states of the FWO system is discretize using the RK4 method while the third state which is fractional order is simulated using Adomian Decomposition Method (ADM) [60]. The ADM method used because the numerical analysis requires more memory [61] to implement in FPGA. Because the ADM algorithm converges fast [60], the first 6 terms are used to get the solution of FWO system as in real cases. So, it is impossible to find the accurate value of $x$ when $t$ takes larger values [62]. Hence, a time discretization method is designed in this paper. In a time interval $t_{\mathrm{i}}$ (initial time) to $t_{\mathrm{f}}$ (final time), the interval is divided into $\left(t_{n}, t_{n+1}\right)$ and the value of $x(n+1)$ at time $t_{n+1}$ is got by applying $x(n)$ at time $t_{n}$ using the relation $x(n+1)=F(x(n))[34],[37]$.

The discrete form of the FWO system (6) is given by,

$$
\begin{aligned}
& x(n+1)=x(n)+\frac{1}{6}\left[K_{x}^{(1)}(n)+2 K_{x}^{(2)}(n)+2 K_{x}^{(3)}(n)+K_{x}^{(4)}(n)\right], \\
& y(n+1)=y(n)+\frac{1}{6}\left[K_{y}^{(1)}(n)+2 K_{y}^{(2)}(n)+2 K_{y}^{(3)}(n)+K_{y}^{(4)}(n)\right], \\
& z(n+1)=\sum_{j=0}^{6} A^{j} \frac{h^{j q}}{\Gamma(j q+1)}
\end{aligned}
$$

where $A_{i}^{j}$ are the intermediate variables with $i=1,2,3$ and $j=0$ to 6 with $h=t_{n+1}-t_{n}$ and $\Gamma(\cdot)$ is the gamma function. Let $A_{1}{ }^{0}=x_{n}, A_{2}{ }^{0}=y_{n}, A_{3}{ }^{0}=z_{n}$. The values of $K_{i}^{j}(n)$ used in RK4 calculations for $i=1$ to 4 and $j=x, y$ are calculated as

$$
\begin{aligned}
& K_{x}^{(1)}(n)=h f_{x}[x(n), y(n), z(n)] \\
& K_{x}^{(2)}(n)=h f_{x}\left[x(n)+\frac{K_{x}^{(1)}(n)}{2}, y(n)+\frac{K_{y}^{(1)}(n)}{2}, z(n)+\frac{K_{z}^{(1)}(n)}{2}\right] \\
& K_{x}^{(3)}(n)=h f_{x}\left[x(n)+\frac{K_{x}^{(2)}(n)}{2}, y(n)+\frac{K_{y}^{(2)}(n)}{2}, z(n)+\frac{K_{z}^{(2)}(n)}{2}\right] \\
& K_{x}^{(4)}(n)=h f_{x}\left[x(n)+\frac{K_{x}^{(3)}(n)}{2}, y(n)+\frac{K_{y}^{(3)}(n)}{2}, z(n)+\frac{K_{z}^{(3)}(n)}{2}\right]
\end{aligned}
$$

Two types of nonlinear terms exist in the FWO system $\left(x_{i}\right)^{2}, x_{i}^{2} x_{j}$ and the six Adomian polynomials are derived in Tab. 1. In this table $x_{i}=x, x_{j}=z, A_{i}{ }^{0}=x(0)$, $A_{j}^{0}=z(0)$. We implement the discrete FOW system (12) in FPGA using the Adomian polynomials and the Kintex 7 (Device $=7 \mathrm{k} 160 \mathrm{t}$ and Package $=\mathrm{fbg} 484 \mathrm{~S}$ ) processors. All the necessary static components such as $h^{q}$, $\frac{\Gamma(2 q+1)}{\Gamma^{2}(q+1)}, h^{2 q}, \quad \frac{\Gamma(3 q+1)}{\Gamma(2 q+1) \Gamma(q+1)}, h^{3 q}, \frac{\Gamma(4 q+1)}{\Gamma(3 q+1) \Gamma(q+1)}, h^{4 q}$, $\frac{\Gamma(5 q+1)}{\Gamma(4 q+1) \Gamma(q+1)}, h^{5 q}$ are calculated before the iteration to increase the processing speed. The step size $h=0.001$ and the commensurate fractional order for implementing the FOW in FPGA is taken as $q=0.95$. The entire discretized FWO system is implemented in System Generator tool in Simulink-Matlab. Figure 8 shows the FWO system (16) 


\begin{tabular}{|c|l|}
\hline Nonlinear Component & \multicolumn{1}{c|}{ Adomian polynomials } \\
\hline & $A_{i}^{1}=\left(A_{i}^{0}\right)^{2}$ \\
& $A_{i}^{2}=2 A_{i}^{0} A_{i}^{1}$ \\
& $A_{i}^{3}=2 A_{i}^{0} A_{i}^{2}+\left(A_{i}^{1}\right)^{2} \frac{\Gamma(2 q+1)}{\Gamma^{2}(q+1)}$ \\
& $A_{i}^{4}=2 A_{i}^{0} A_{i}^{3}+2 A_{i}^{2} A_{i}^{1} \frac{\Gamma(3 q+1)}{\Gamma(2 q+1) \Gamma(q+1)}$ \\
& $A_{i}^{5}=2 A_{i}^{0} A_{i}^{4}+\left[2 A_{i}^{3} A_{i}^{1}+\left(A_{i}^{2}\right)^{2}\right] \frac{\Gamma(4 q+1)}{\Gamma(3 q+1) \Gamma(q+1)}$ \\
& $A_{i}^{6}=2 A_{i}^{0} A_{i}^{5}+\left[2 A_{i}^{3} A_{i}^{2}+2 A_{i}^{4} A_{i}^{1}\right] \frac{\Gamma(5 q+1)}{\Gamma(4 q+1) \Gamma(q+1)}$ \\
\hline & $A_{k}^{1}=\left(A_{i}^{0}\right)^{2} A_{j}^{0}$ \\
& $A_{k}^{2}=2 A_{i}^{0} A_{i}^{1} A_{j}^{0}$ \\
& $A_{k}^{3}=2 A_{i}^{0} A_{i}^{2} A_{j}^{0}+\left(A_{i}^{1}\right)^{2} A_{j}^{0} \frac{\Gamma(2 q+1)}{\Gamma^{2}(q+1)}$ \\
& $A_{k}^{4}=2 A_{i}^{0} A_{i}^{3} A_{j}^{0}+2 A_{i}^{2} A_{i}^{1} A_{j}^{0} \frac{\Gamma(3 q+1)}{\Gamma(2 q+1) \Gamma(q+1)}$ \\
& $A_{k}^{5}=2 A_{i}^{0} A_{i}^{4} A_{j}^{0}+\left[2 A_{i}^{3} A_{i}^{1} A_{j}^{0}+\left(A_{i}^{2}\right)^{2} A_{j}^{0}\right] \frac{\Gamma(4 q+1)}{\Gamma(3 q+1) \Gamma(q+1)}$ \\
& $A_{k}^{6}=2 A_{i}^{0} A_{i}^{5} A_{j}^{0}+\left[2 A_{i}^{3} A_{i}^{2} A_{j}^{0}+2 A_{i}^{4} A_{i}^{1} A_{j}^{0}\right] \frac{\Gamma(5 q+1)}{\Gamma(4 q+1) \Gamma(q+1)}$ \\
\hline
\end{tabular}

Tab. 1. Adomian polynomials of the nonlinear components in the third state ' $Z$ ' of FWO system.

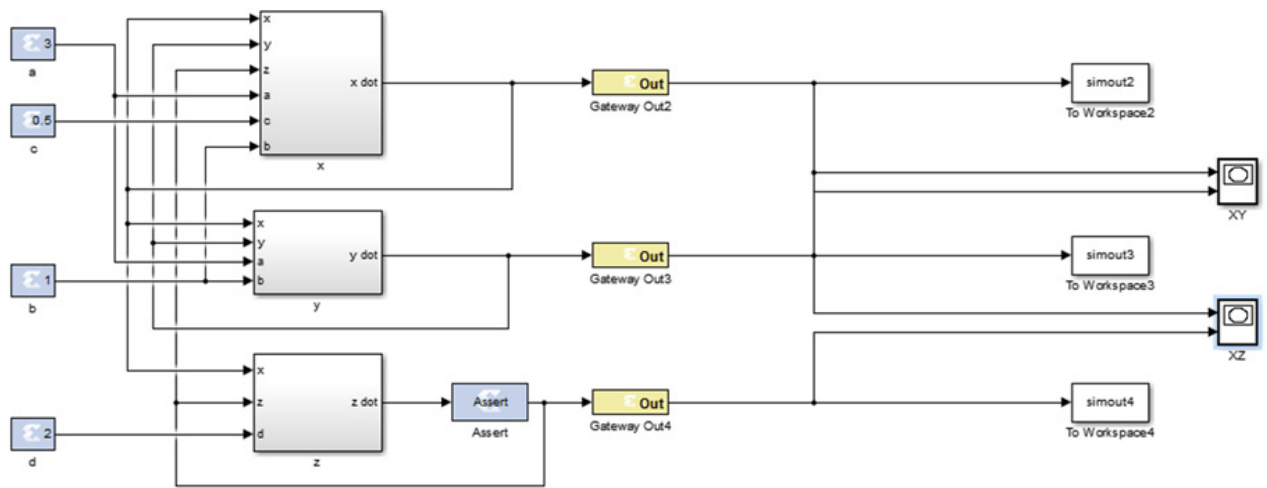

Fig. 8. The FWO system implemented in Simulink with the Xilinx system generator token.

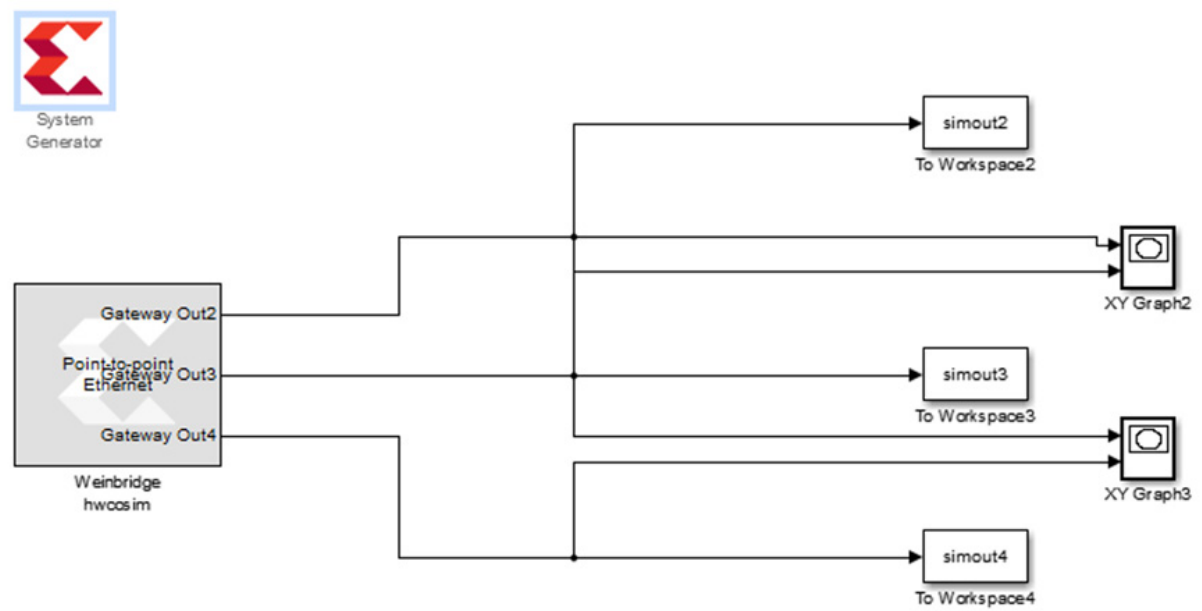

Fig. 9. The hardware-software co-simulation block generated for Kintex-7 (KC-705) with point to point Ethernet connectivity. 


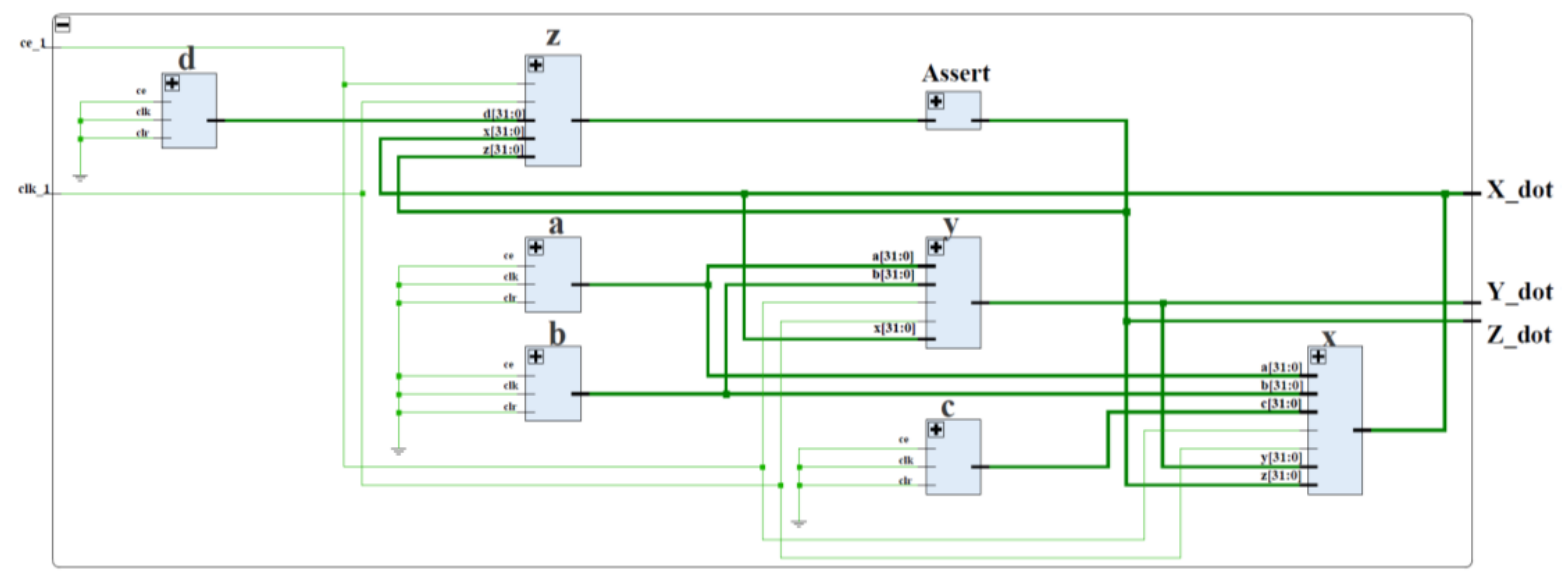

Fig. 10. The RTL schematics of the FWO system.

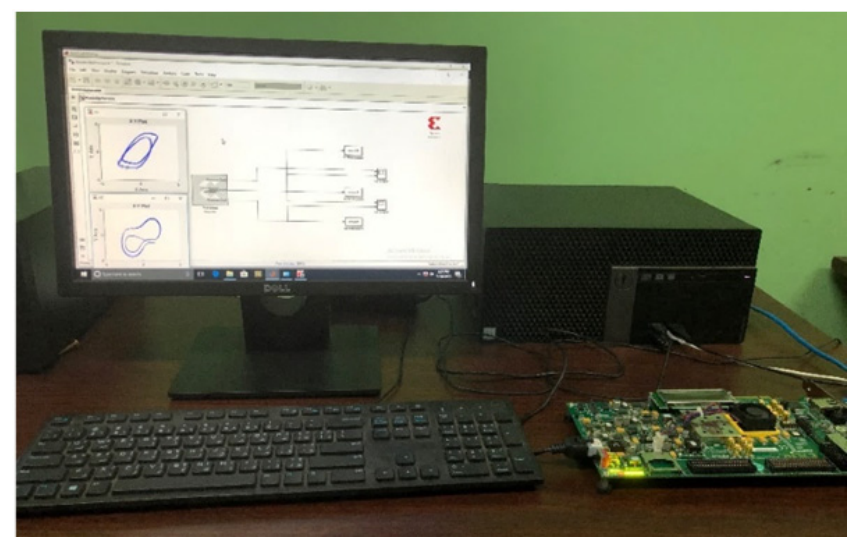

Fig. 11. The experimental setup for hardware-software cosimulation using KC-705 board.
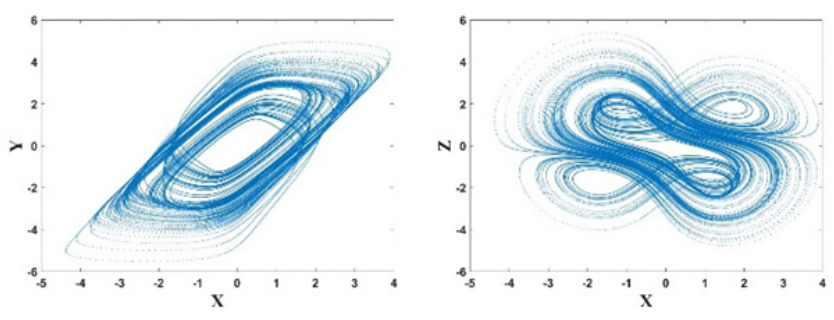

Fig. 12. The 2D phase portraits generated using the cosimulation.

implemented in Matlab-Simulink using Xilink block set. To conduct the experiment, we have adopted hardwaresoftware co-simulation. Kintex-7 KC 705 board is used to co-simulate with point to point Ethernet connectivity. Figure 9 shows the point to point Ethernet block generated for hardware-software co-simulation and Figure 10 presents the register transfer logic (RTL) of the FWO system. Figure 11 shows the experimental setup for the co-simulation using the Kintex-7 (KC-705 board) and Figure 12 presents the generated phase portraits.

\section{Conclusion}

In this paper a modified third order Wien bridge oscillator with fractional order memristor component was proposed. Various dynamical properties of the proposed oscillator are investigated. The proposed oscillator had two stable and one unstable equilibrium points and showed a positive Lyapunov exponent for some parameters. Bifurcation diagrams of the system with respect to changing parameter $a$ and fractional order were investigated. The feature of multistability is captured using forward and backward continuation bifurcation diagrams. Experimental investigations of the FWO system were done using FPGA while the integer order states were implemented using RK4 and fractional order state was implemented using Adomian decomposition.

\section{Acknowledgments}

This work was supported by the Defence University of Ethiopia research grant No DU/IRD/002, Iran Science Elites Federation Grant No M - 97171, by the National Nature Science Foundation of China (Grant No. 61871230), the Natural Science Foundation of Jiangsu Province (Grant No. : BK20181410).

\section{References}

[1] NAZARIMEHR, F., JAFARI, S., CHEN, G., et al. A tribute to J.C. Sprott. International Journal of Bifurcation and Chaos, 2017, vol. 27 , no. 14 , p. 1-14. DOI: $10.1142 / \mathrm{S} 0218127417502212$

[2] GotThans, T., SPROTT, J. C., PETRZELA, J. Simple chaotic flow with circle and square equilibrium. International Journal of Bifurcation and Chaos, 2016, vol. 26, no. 08, p. 1-8. DOI: $10.1142 / \mathrm{S} 0218127416501376$

[3] PHAM, V.-T., JAFARI, S., VOLOS, C., et al. A chaotic system with rounded square equilibrium and with no-equilibrium. OptikInternational Journal for Light and Electron Optics, 2017, vol. 130, p. 365-371. DOI: 10.1016/j.ijleo.2016.10.100

[4] KVARDA, P. Identifying the deterministic chaos by using the Lorenz maps. Radioengineering, 2000, vol. 9, no. 4, p. 32-33.

[5] LORENZ, E. The butterfly effect. World Scientific Series on Nonolinear Science Series A, 2001, vol. 39, p. 91-94. DOI: 10.1142/9789812386472_0007

[6] DUDKOWSKI, D., PRASAD, A., KAPITANIAK, T. Perpetual points and hidden attractors in dynamical systems. Physics Letters A, 
2015, vol. $379, \quad$ no. $40-41, \quad$ p. $2591-2596 . \quad$ DOI: 10.1016/j.physleta.2015.06.002

[7] NAZARIMEHR, F., SAEDI, B., JAFARI, S., et al. Are perpetual points sufficient for locating hidden attractors? International Journal of Bifurcation and Chaos, 2017, vol. 27, no. 3, p. 1-7. DOI: $10.1142 / \mathrm{S} 0218127417500377$

[8] LI, C., SPROTT, J. C., THIO, W. Linearization of the Lorenz system. Physics Letters A, 2015, vol. 379, no. 10, p. 888-893. DOI: $10.1016 /$ j.physleta.2015.01.003

[9] CHEN, G., UETA, T. Yet another chaotic attractor. International Journal of Bifurcation and Chaos, 1999, vol. 9, no. 7, p. 1465-1466. DOI: $10.1142 /$ S0218127499001024

[10] LORENZ, E. N. Deterministic nonperiodic flow. Journal of the Atmospheric Sciences, 1963, vol. 20, no. 2, p. 130-141. DOI: 10.1175/1520-0469(1963)020<0130:DNF $>2.0 . \mathrm{CO} ; 2$

[11] WANG, X., CHEN, G. A chaotic system with only one stable equilibrium. Communications in Nonlinear Science and Numerical Simulation, 2012, vol. 17, no. 3, p. 1264-1272. DOI: 10.1016/j.cnsns.2011.07.017

[12] WANG, X., CHEN, G. Constructing a chaotic system with any number of equilibria. Nonlinear Dynamics, 2013, vol. 71, no. 3, p. 429-436. DOI: 10.1007/s11071-012-0669-7

[13] WEI, Z. Dynamical behaviors of a chaotic system with no equilibria. Physics Letters A, 2011, vol. 376, no. 2, p. 102-108. DOI: 10.1016/j.physleta.2011.10.040

[14] GOTTHANS, T., PETRŽELA, J. New class of chaotic systems with circular equilibrium. Nonlinear Dynamics, 2015, vol. 81, no. 3, p. 1143-1149. DOI: 10.1007/s11071-015-2056-7

[15] JAFARI, S., SPROTT, J., GOLPAYEGANI, S. M. R. H Elementary quadratic chaotic flows with no equilibria. Physics Letters A, 2013, vol. 377, no. 9, p. 699-702. DOI: 10.1016/j.physleta.2013.01.009

[16] ABDOLMOHAMMADI, H. R., KHALAF, A. J. M., PANAHI, S., et al. A new 4D chaotic system with hidden attractor and its engineering applications: Analog circuit design and field programmable gate array implementation. Pramana, 2018, vol. 90, no. 6, p. 7. DOI: $10.1007 / \mathrm{s} 12043-018-1569-2$

[17] BAO, B., BAO, H., WANG, N., et al. Hidden extreme multistability in memristive hyperchaotic system. Chaos, Solitons \& Fractals, 2017, vol. 94, p. 102-111. DOI: 10.1016/j.chaos.2016.11.016

[18] BUSCARINO, A., FORTUNA, L., FRASCA, M., et al. A chaotic circuit based on Hewlett-Packard memristor. Chaos: An Interdisciplinary Journal of Nonlinear Science, 2012, vol. 22, no. 2, p. 1-9. DOI: 10.1063/1.4729135

[19] PETRŽElA, J., HRUBOŠ, Z., GOTTHANS, T. Modeling deterministic chaos using electronic circuits. Radioengineering, 2011, vol. 20, no. 2, p. 438-444. ISSN 1210-2512

[20] CHUA, L. Memristor - the missing circuit element. IEEE Transactions on Circuit Theory, 1971, vol. 18, no. 5, p. 507-519. DOI: 10.1109/TCT.1971.1083337

[21] CHUA, L. O. The fourth element. Proceedings of the IEEE, 2012, vol. 100 , no. $6, \quad$ p. $1920-1927$. DOI: 10.1109/JPROC.2012.2190814

[22] STRUKOV, D. B., SNIDER, G. S., STEWART, D. R., et al. The missing memristor found. Nature, 2008, vol. 453, no. 7191, p. $80-83$. DOI: $10.1038 /$ nature 06932

[23] BAO, B.-C., XU, Q., BAO, H., et al. Extreme multistability in a memristive circuit. Electronics Letters, 2016, vol. 52, no. 12, p. 1008-1010. DOI: 10.1049/el.2016.0563

[24] BAO, B., JIANG, T., XU, Q., et al. Coexisting infinitely many attractors in active band-pass filter-based memristive circuit.
Nonlinear Dynamics, 2016, vol. 86, no. 3, p. 1711-1723. DOI: $10.1007 / \mathrm{s} 11071-016-2988-6$

[25] CORINTO, F., FORTI, M. Memristor circuits: Flux-charge analysis method. IEEE Transactions on Circuits and Systems, 2016, vol. 63, no. 11, p. 1997-2009. DOI: 10.1109/TCSI.2016.2590948

[26] LI, C., THIO, W. J.-C., IU, H. H.-C., et al. A memristive chaotic oscillator with increasing amplitude and frequency. IEEE Access, 2018, vol. 6, p. 12945-12950. DOI: 10.1109/ACCESS.2017.2788408

[27] SÁNCHEZ-LÓPEZ, C., CARBAJAL-GÓMEZ, V. H., CARRASCO-AGUILAR, M., et al. Fractional-order memristor emulator circuits. Complexity, 2018, p. 1-10. DOI: 10.1155/2018/2806976

[28] WANG, F. Z., SHI, L., WU, H., et al. Fractional memristor. Applied Physics Letters, 2017, vol. 111, no. 24, p. 1-5. DOI: 10.1063/1.5000919

[29] FOUDA, M., RADWAN, A. On the fractional-order memristor model. Journal of Fractional Calculus and Applications, 2013, vol. 4, no. 1, p. 1-7. ISSN: 2090-585

[30] TENG, L., IU, H. H., WANG, X., et al. Chaotic behavior in fractional-order memristor-based simplest chaotic circuit using fourth degree polynomial. Nonlinear Dynamics, 2014, vol. 77, no. 1-2, p. 231-241. DOI: $10.1007 / \mathrm{s} 11071-014-1286-4$

[31] TALUKDAR, A., RADWAN, A. G., SALAMA, K. N. Generalized model for memristor-based Wien family oscillators. Microelectronics Journal, 2011, vol. 42, no. 9, p. 1032-1038. DOI: $10.1016 /$ j.mejo.2011.07.001

[32] XU, Q., LIN, Y., BAO, B., et al. Multiple attractors in a non-ideal active voltage-controlled memristor based Chua's circuit. Chaos, Solitons \& Fractals, 2016, vol. 83, p. 186-200. DOI: 10.1016/j.chaos.2015.12.007

[33] XU, Q., ZHANG, Q., BAO, B., et al. Non-autonomous secondorder memristive chaotic circuit. IEEE Access, 2017, vol. 5, p. 21039-21045. DOI: 10.1109/ACCESS.2017.2727522

[34] KHALAF, A. J. M., KAPITANIAK, T., RAJAGOPAL, K., et al. A new three-dimensional chaotic flow with one stable equilibrium: dynamical properties and complexity analysis. Open Physics, vol. 16, no. 1, p. 260-265. DOI: 10.1515/phys-2018-0037

[35] LI, C., SPROTT, J. C. Multistability in the Lorenz system: a broken butterfly. International Journal of Bifurcation and Chaos, 2014, vol. 24, no. 10, p. 1-7. DOI: $10.1142 / \mathrm{S} 0218127414501314$

[36] LI, C., HU, W., SPROTT, J. C., et al. Multistability in symmetric chaotic systems. The European Physical Journal Special Topics, 2015 , vol. 224 , no. 8 , p. $1493-1506$. DOI: $10.1140 /$ epjst/e2015$02475-\mathrm{x}$

[37] BAO, H., WANG, N., WU, H., et al. Bi-stability in an improved memristor-based third-order Wien-bridge oscillator. IETE Technical Review, 2018, p. $1-8 . \quad$ DOI: $10.1080 / 02564602.2017 .1422395$

[38] BALEANU, D., DIETHELM, K., SCALAS, E., et al. Fractional Calculus: Models and Numerical Methods. World Scientific Pub Co, 2016. ISBN: 9813140054

[39] LAKSHMIKANTHAM, V., VATSALA, A. Basic theory of fractional differential equations. Nonlinear Analysis: Theory, Methods \& Applications, 2008, vol. 69, no. 8, p. 2677-2682. DOI: 10.1016/j.na.2007.08.042

[40] DIETHELM, K. The Analysis of Fractional Differential Equations: An Application-Oriented Exposition Using Differential Operators of Caputo Type. Springer, 2010. ISBN: 3642145744

[41] PETRÁŠ, I. Method for simulation of the fractional order chaotic systems. Acta Montanistica Slovaca, 2006, vol. 11, no. 4, p. $273-277$. ISSN: $1335-1788$ 
[42] TRZASKA, Z. Matlab solutions of chaotic fractional order circuits. Chapter 19 in: Assi, A. (ed.) Engineering Education and Research Using MATLAB, 2011. DOI: 10.5772/23144

[43] RAJAGOPAL, K., AKGUL, A., JAFARI, S., et al. Chaotic chameleon: Dynamic analyses, circuit implementation, FPGA design and fractional-order form with basic analyses. Chaos, Solitons \& Fractals, 2017, vol. 103, p. 476-487. DOI: 10.1016/j.chaos.2017.07.007

[44] RAJAGOPAL, K., KARTHIKEYAN, A., SRINIVASAN, A. Dynamical analysis and FPGA implementation of a chaotic oscillator with fractional-order memristor components. Nonlinear Dynamics, 2018, vol. 91, no. 3, p. 1491-1512. DOI: $10.1007 / \mathrm{s} 11071-017-3960-9$

[45] TLELO-CUAUTlE, E., DE LA FRAGA, L. G., PHAM, V.-T., et al. Dynamics, FPGA realization and application of a chaotic system with an infinite number of equilibrium points. Nonlinear Dynamics, 2017, vol. 89, no. 2, p. 1129-1139. DOI: $10.1007 / \mathrm{s} 11071-017-3505-2$

[46] CHUA, L. O., KANG, S. M. Memristive devices and systems. Proceedings of the IEEE, 1976, vol. 64, no. 2, p. 209-223. DOI: 10.1109/PROC.1976.10092

[47] ABDELOUAHAB, M.-S., LOZI, R. Hopf bifurcation and chaos in simplest fractional-order memristor-based electrical circuit. Indian Journal of Industrial and Applied Mathematics, 2015, vol. 6, no. 2 , p. 105-119. DOI: 10.5958/1945-919X.2015.00009.2

[48] ZHANG, Y., XIE, X., LUO, G. Multiple nested basin boundaries in nonlinear driven oscillators. Communications in Nonlinear Science and Numerical Simulation, 2017, vol. 44, p. 220-228. DOI: 10.1016/j.cnsns.2016.08.010

[49] RAJAGOPAL, K., KARTHIKEYAN, A., DURAISAMY, P., et al. Bifurcation, chaos and its control in a fractional order power system model with uncertainties. Asian Journal of Control, 2019, vol. 21, no. 1, p. 184-193. DOI: 10.1002/asjc.1826

[50] DIETHELM, K. An algorithm for the numerical solution of differential equations of fractional order. Electronic Transactions on Numerical Analysis, 1997, vol. 5, p. 1-6.

[51] DIETHELM, K., FORD, N. J. Analysis of fractional differential equations. Journal of Mathematical Analysis and Applications, 2002, vol. 265, no. 2, p. 229-248. DOI: 10.1006/jmaa.2000.7194

[52] SUN, H., ABDELWAHAB, A., ONARAL, B. Linear approximation of transfer function with a pole of fractional power. IEEE Transactions on Automatic Control, 1984, vol. 29, no. 5, p. 441-444. DOI: 10.1109/TAC.1984.1103551

[53] DIETHELM, K., FREED, A. D. The FracPECE subroutine for the numerical solution of differential equations of fractional order. In Heinzel, S., Plesser, T. (eds.), Forschung und wissenschaftliches Rechnen, 1998, p. 57-71.

[54] DIETHELM, K., FORD, N. J., FREED, A. D. Detailed error analysis for a fractional Adams method. Numerical Algorithms, 2004, vol. 36, no. 1, p. 31-52. DOI: 10.1023/B:NUMA.0000027736.85078.be

[55] KVARDA, P. Identifying the deterministic chaos by using the Lyapunov exponents. Radioengineering, 2001, vol. 10, no. 2, p. $38-40$. ISSN: $1210-2512$

[56] WOLF, A., SWIFT, J. B., SWINNEY, H. L., et al. Determining Lyapunov exponents from a time series. Physica D: Nonlinear Phenomena, 1985, vol. 16, no. 3, p. 285-317. DOI: 10.1016/01672789(85)90011-9

[57] GARRAPPA, R. Predictor-corrector PECE method for fractional differential equations. MATLAB Central File Exchange [File ID: 32918], 2011

[58] DANCA, M.-F. Lyapunov exponents of a class of piecewise continuous systems of fractional order. Nonlinear Dynamics, 2015, vol. 81, no. 1-2, p. 227-37. DOI: 10.1007/s11071-015-1984-6
[59] RAJAGOPAL, K., KARTHIKEYAN, A., SRINIVASAN, A. K. FPGA implementation of novel fractional-order chaotic systems with two equilibriums and no equilibrium and its adaptive sliding mode synchronization. Nonlinear Dynamics, 2017, vol. 87, no. 4, p. 2281-2304. DOI: 10.1007/s11071-016-3189-z

[60] ADOMIAN, G. A review of the decomposition method and some recent results for nonlinear equations. Mathematical and Computer Modelling, 1990, vol. 13, no. 7, p. 17-43. DOI: 10.1016/08957177(90)90125-7

[61] HE, S. B., SUN, K. H., WANG, H. H. Solution of the fractionalorder chaotic system based on Adomian decomposition algorithm and its complexity analysis. Acta Physica Sinica, 2014, vol. 63, no. 3, p. 1-8. DOI: 10.7498/aps.63.030502 (in Chinese)

[62] CAPONETTO, R., FAZZINO, S. An application of Adomian decomposition for analysis of fractional-order chaotic systems. International Journal of Bifurcation and Chaos, 2013, vol. 23, no. 3 , p. $1-7$. DOI: $10.1142 / \mathrm{S} 0218127413500508$

\section{About the Authors ...}

Karthikeyan RAJAGOPAL is presently working as an Sr. Research member and Professor in the Center for Nonlinear Dynamics, Defence University, Ethiopia. He has completed his Ph.D. in Electronics and Communication Engineering with specializing in Chaos-based Secure Communication Engineering. His post-graduation was in embedded system technologies with emphasis on real-time targets programming. He has over 100 international journal papers indexed in SCI and his present research areas include fractional order nonlinear systems and control, time delay systems, FPGA and LabVIEW implementations of fractional order systems.

Chunbiao LI was born in Baoying, Yangzhou, China, in 1971. He received his B.S., M.S., and Ph.D. degrees in 1994, 2004 and 2009 in Nanjing, China. He is currently a professor in the School of Electronic \& Information Engineering, Nanjing University of Information Science \& Technology. His research interests include weak signal detection, secure communication, nonlinear circuits \& systems and corresponding applications. He has received several awards for his teaching and research in Jiangsu Province. From 2010 to 2014 he was a postdoctoral fellow in the School of Information Science and Engineering at Southeast University. He was a visiting scholar in the Dept. of Physics, University of Wisconsin-Madison in 2012.

Fahimeh NAZARIMEHR was born in 1990 in Qazvin, Iran. She receives the B.Sc. degree in Biomedical Engineering at Shahed University in 2012 and the M.Sc. degree at Sharif University of Technology in 2014. She receives the Ph.D. in Biomedical Engineering at Amirkabir University of Technology in 2018. Currently she is a researcher in biomedical engineering department at Amirkabir University of Technology. Her research interests include chaos theory and its application in biological signals and systems, nonlinear dynamics, bifurcation analysis, dynamical systems in neuroscience, bio-electricity and quantitative approaches, feature extraction and classification of signals. 
Anitha KARTHIKEYAN completed her Ph.D. in Electronics and Communication Engineering with specializing in Discrete Chaotic System Synchronization for Applications in Cryptography. Her post-graduation was in embedded system technologies with emphasis on real-time targets programming. She is presently working as an associate professor of the Center for Nonlinear Dynamics, Defence University, Ethiopia. She has published over 60 articles in SCI journals of repute.

Prakash DURAISAMY completed his Ph.D. in Mechanical Engineering with specializing in Dynamic Analysis and Nonlinearity Suppression in Fractional-Order Uncertain Electro-Mechanical Systems. His post-graduation was in Computer Aided Design. He is presently working as an assistant professor at the Dept. of Production Engineering, Defence University-College of Engineering, Ethiopia. He has published 13 articles in SCI journals and his present research areas include fractional order nonlinear systems and nonlinear vibration of real time systems.

Sajad JAFARI (corresponding author) was born in Kermanshah, Iran, in 1983. He received his B.Sc., M.S., and Ph.D. degrees in Biomedical Engineering in 2005, 2008, 2013 from the Biomedical Engg. Dept., Amirkabir University of Technology, Tehran, Iran. He is currently an assistant professor there (since 2013). His research interests include artificial intelligence, optimization, pattern recognition and especially nonlinear and chaotic signals and systems. He has published more than 100 SCI (ISI) indexed papers. 